\title{
A história da tradução do Brasil: questões de pesquisa ${ }^{1}$
}

José Antonio Sabio Pinilla*

\section{História da Tradução e Estudos da Tradução}

O primeiro teórico a descrever os Estudos da Tradução como uma disciplina foi o tradutor e professor holandês James S. Holmes na sua célebre comunicação The Name and the Nature of Translations Studies, apresentada no III Congresso Internacional de Linguística Aplicada em Copenhague, Dinamarca, de 21 a 26 de agosto de 1972 (publicada, entre outras edições, em 1988). A este tradutor de poesia devemos uma primeira descrição dos Estudos da Tradução em dois ramos: puro e aplicado. Os estudos puros subdividem-se em teóricos e descritivos; por sua vez, os estudos teóricos em gerais e parciais. Ao tratar dos estudos descritivos, orientados ao produto (a descrição e comparação de traduções em um plano sincrônico e diacrônico) e à função (a descrição da função da tradução no contexto sociocultural), Holmes fala da variante diacrônica. Isso nos levaria, no produto, a uma história geral da tradução. Na função, nos levaria a ver a sua influência em histórias de traduções e histórias literárias (HOLMES, 1988, p. 72). Ao final de seu artigo, o autor chama atenção para a relação dialética que as três subdivisões mantêm às quais é preciso incorporar duas dimensões de

\footnotetext{
${ }^{1}$ Este trabalho foi uma conferência proferida no dia 3 de julho de 2018, no Programa de Pós-Graduação Estudos em Tradução da Universidade Federal de Santa Catarina (Florianópolis).

Pode consultar-se em: https://www.youtube.com/watch?v=wqYK6EKodJE

${ }^{*}$ Universidade de Granada (Espanha).
} 
análises: a histórica e a metodológica (ou metateórica). Contudo, no mapa de Holmes, elaborado por Toury (1991, p. 181; 1995, p. 10), a História da Tradução não vem referida como campo de estudo independente. A última reformulação do mapa, de autoria de Vandepitte (2008), também não contempla a História da Tradução como âmbito independente, porém, a autora considera na seção sobre estudos de grande abrangência (umbrella studies), que o espaço e o tempo são perspectivas tradicionais para o estudo da tradução que podem abarcar a "história dos estudos de tradução" (VANDEPITTE, 2008, p. 579). No Apêndice, Vandepitte apresenta um thesaurus de estudos de tradução, no qual figura a história da tradução, que não obstante, é tratada tangencialmente. Como assinala Seruya (2015, p. 222), “o lugar desta não é o de um «Lead Term» na disciplina, nem sequer um «Narrow Term», mas apenas um «Related Term». Eis um indício significativo da relevância secundária da história da tradução nos interesses dos ET." Apesar dessa relevância secundária, defendemos que a História da Tradução é uma área de pleno direito dentro dos Estudos da Tradução. Segundo nosso ponto de vista, é preciso diferenciar a dimensão ou a variável histórica, apontada por Hurtado Albir (1994, p. 35), que atravessa toda a disciplina, do estudo propriamente histórico de que se ocuparia a História da Tradução, cujos fundamentos se alicerçam na pesquisa metodológica das fontes.

O mapa de Holmes foi adaptado por Adriana Pagano e Maria Lúcia Vasconcellos em 2003 à situação dos Estudos da Tradução do Brasil. As autoras fizeram uma proposta a partir dos trabalhos acadêmicos publicados nas décadas de 1980 e 1990 e incluíram a Historiografia nos estudos teóricos gerais como marco teórico interdisciplinar, junto com a Antropologia, a Psicologia Cognitiva e os Estudos Culturais (PAGANO; VASCONCELLOS, 2003, p. 15). Frota (2007) também afirma que a "a área da historiografia, ao lado das de mídia e corpora são as que me parecem trazer o que há de mais novo nos estudos brasileiros da tradução deste último decênio, seja por seu surgimento ou por sua consolidação" (FROTA, 2007, p. 152).

Do ponto de vista conceitual convém diferenciar entre "história" e "historiografia". Nesse sentido, Lambert (1993, p. 4) considera que a primeira remete principalmente ao material histórico, enquanto a segunda 
se refere ao discurso do historiador. Por sua vez, Delisle (2008, p. 82) menciona três significados de historiografia: a) a arte de escrever a história; b) o conjunto de obras históricas produzidas num tempo específico ou numa determinada disciplina, e c) a perspectiva histórica dessa produção, interessada na evolução dos métodos de pesquisa do historiador e nos modos de escrever a história. Finalmente, D'hulst (2010, p. 397-398) estabelece três níveis ou subdisciplinas: a história, entendida como "a sequência de eventos, ideias e discursos"; a historiografia, definida como "a história das histórias", que aproveita os conceitos, a metodologia e os métodos específicos de outras áreas de conhecimento, como a Linguística, Filosofia ou Literatura; e a metahistoriografia, que se refere à reflexão explícita sobre os conceitos e métodos de escrita da história, bem como a problemas epistemológicos e metodológicos relacionados a esses conceitos e métodos que têm a ver com questões espaciais, temporais, ideológicas e do acesso a fontes e a sua interpretação.

Muitas são as questões envolvidas no estudo da História da Tradução, entre elas a sua definição e objeto, o âmbito de ação e a metodologia da pesquisa histórica (PINILLA; PULIDO et al., 2017), porém, de maneira breve, poderíamos assinalar quatro considerações gerais que o historiador da tradução deve levar em conta: a) evitar olhar para os fatos passados com os preconceitos e conhecimentos do presente; b) ligar a interpretação do passado ao contexto de seu tempo; c) pesquisar as condições de produção e recepção das traduções, a função social da tradução e o papel dos agentes e tradutores, e d) propor, na medida do possível, uma periodização própria do estudo histórico da tradução.

\section{A história da tradução do Brasil}

Foi Berman (1989, p. 679) o primeiro a assinalar que por trás das teorias contemporâneas de tradução há uma problemática específica de um espaço cultural determinado. Assim, uma primeira questão controversa é como delimitar espacialmente nosso objeto de estudo; neste trabalho, adotamos a categoria "Brasil", cientes de que este espaço é complexo e mantém relações com outras categorias espaciais do ponto de vista histórico-cultural: América Portuguesa, América Latina, Ibero-américa, América Hispânica, Espanhola 
ou Hispano-américa. Uma abordagem da história da tradução do Brasil ${ }^{2}$ deve considerar as relações que mantém com a América Latina. O Grupo HISTAL (História da Tradução na América Latina), que desenvolve desde 2001 uma pesquisa na área de história da tradução centrada fundamentalmente no âmbito hispânico, é pioneiro nesta pesquisa e inclui aspectos da história da tradução do Brasil nas seções de bibliografia e de documentos, diferentemente de outros projetos que deixam de lado os tópicos brasileiros. Referimo-nos, sobretudo, aos trabalhos dedicados à história da tradução na América Espanhola, organizados por Lafarga e Pegenaute (2012a, 2012b, 2013), em cuja descrição os autores silenciam conscientemente o papel da língua portuguesa no continente americano:

É evidente, porém, o critério "hispanista" de um projeto que oferece materiais para elaborar uma história da tradução de e para o espanhol na América, mas que, ao deixar de lado, entre outros, o imenso âmbito da tradução no Brasil, produz um recorte que impede uma percepção mais ampla e mais exata daquilo que poderia ser uma história da tradução na América Latina $^{3}$ (PAGNI, 2014, p. 211).

Outra questão problemática da história da tradução do Brasil é a sua relação com Portugal, historiar a tradução brasileira exige uma reflexão sobre a sua origem lusitana. Nesse sentido, podemos nos interrogar sobre os limites temporais em função do olhar brasileiro ou português: incluímos o Brasil na história da tradução de Portugal até a independência? A partir de quando podemos falar em história da tradução brasileira? Quais as fronteiras históricas compartilhadas e como diferenciar a história de um lado e do outro? Não seria melhor falar tanto para Portugal quanto para o Brasil de “história da tradução luso-brasileira" para certos períodos? Quais as relações

\footnotetext{
2 Optamos propositadamente pelo uso do sintagma "do Brasil" no título deste trabalho para reforçar o sentido "brasileiro" da história da tradução, ainda que no decurso do artigo possa aparecer como sinônimo do sintagma "no Brasil"; o nosso intuito é ressaltar a história da tradução brasileira como objeto específico de pesquisa e não tanto outros tipos de estudos históricos da tradução em andamento no Brasil. ${ }^{3}$ Tradução própria do original: "Es evidente, sin embargo, el criterio "hispanista" de un proyecto que ofrece materiales para elaborar una historia de la traducción del y al español en América, pero que, al dejar de lado, entre otros, el inmenso ámbito de la traducción en Brasil, produce un recorte que impide una percepción más amplia y más ajustada de lo que podría ser una historia de la traducción en América Latina" (PAGNI, 2014, p. 2011).
} 
entre ambos os países e os seus reflexos na tradução? Como influíram as políticas linguísticas e as diferentes normas ortográficas na produção de traduções? Quais os contatos e os discursos entre os tradutores brasileiros em Portugal (OLIVEIRA HARDEN, 2009, 2010, 2011) e os tradutores portugueses no Brasil?

\section{O que foi pesquisado?}

Existem várias aproximações sobre a evolução dos Estudos da Tradução no Brasil (PAGANO; VASCONCELLOS, 2003; MARTINS, 2005; FROTA, 2007; GUERINI; TORRES; COSTA, 2013; MILTON, 2014) que analisam esta disciplina nos âmbitos acadêmico, institucional e investigador. Como apontou Frota (2007, p. 150), a pesquisa desenvolvida pelo Núcleo de Estudos da Tradução da Universidade Federal de Santa Catarina (UFSC), com nomes como Andréia Guerini, Marie-Hélène Torres ou Walter Carlos Costa, é pioneira na construção de "uma primeira história da literatura traduzida no Brasil entre 1970 e 2000", além de outras obras de referência como antologias sobre tradução e dicionários de tradutores. Como aconteceu em outros países, o estudo histórico da tradução surgiu, no Brasil, ao longo dos anos noventa do século passado. Esse interesse pela história ganhou maior relevo em 1996, ano da publicação de um artigo de Marcia Martins em que apresenta algumas considerações sobre a escrita da história da tradução para fazer "um convite à ação" (MARTINS, 1996, p. 48), que Lia Wyler, o primeiro grande nome da pesquisa histórica da tradução brasileira, definia em 2005 como um promissor âmbito de pesquisa.

A "virada histórica" que se produz no início do século XXI, apontada por Pagano (2001, p. 140), tem como ponto de referência o livro Línguas, poetas e bacharéis (2003) que Wyler intitula "uma crônica da tradução do Brasil". Antes, em 1998, Wyler tinha elaborado em colaboração com Barbosa o verbete Brazil Tradition para a Encyclopedia of Translation Studies, editada por Mona Baker e Kirsten Malmkjær. No entanto, a visão panorâmica oferecida por Wyler em seu livro constitui - a nosso entender - o fato marcante na investigação sobre a história da tradução brasileira.

A obra é composta de uma introdução e seis capítulos (dois deles foram publicados no livro coletivo Emerging Views on Translation History in 
Brazil, editado por John Milton em 2001), que recolhem, em ordem cronológica, diversos temas desde o descobrimento em 1500 até o reconhecimento legal da profissão de tradutor em 1979. A invisibilidade do tradutor brasileiro a partir das ideias de Venuti, a reivindicação da profissão e o seu estatuto acadêmico são pontos centrais desta introdução. Wyler constata a escassez de estudos históricos e considera José Paulo Paes (1990) o pioneiro da história da tradução do Brasil, a qual "apenas começou a ser registrada, mas já nos propõe questões bem intrigantes" (WYLER, 2003, p. 27). A autora e tradutora oferece, de maneira inovadora, uma síntese clara da história da tradução oral e escrita, com base em uma interpretação econômica e mercantil da prática tradutória, acompanhada de muitas questões de pesquisa ainda não exploradas. Desse modo, o livro é um guia que permite futuros desdobramentos.

Encontramos novas sugestões de pesquisa, complementares às apontadas no livro de Wyler, na apresentação do número especial Contribuições para uma historiografia da tradução, da revista Tradução em Revista (2010), em que John Milton e Marcia Martins adaptam as perguntas tradicionais da retórica à situação brasileira, formuladas por D'hulst em Why and How to Write Translation Histories (2001), propondo alguns campos de ação:

\footnotetext{
Há áreas da história de tradução totalmente virgens, dentro e fora do Brasil. Entre elas podemos mencionar a história do ensino de tradução; a história da interpretação; a história da tradução na mídia; e a tradução e interpretação nas comunidades de imigrantes: aqui no Brasil não existem estudos sobre a tradução dentro das comunidades italiana, alemã, japonesa, russa, ucraniana, polonesa, chinesa, coreana etc., e a tradução entre as línguas indígenas e o português (MILTON; MARTINS, 2010, p. 5).
}

Outro trabalho que atualiza a investigação histórica da tradução brasileira a partir de uma abordagem cronológica é o artigo História da tradução no Brasil: percursos seculares (2016) de Dennys Silva-Reis e John Milton. O roteiro por séculos, que se divide em dois grandes eixos, história da tradução oral (ou interpretação) e história da tradução escrita, complementa o percurso oferecido por Wyler. A visão dada por Silva-Reis e 
Milton, desde o século XVI até o século XXI, é muito sugerente e proporciona novos materiais para desenvolver, apesar de os autores considerarem o seu trabalho uma "visão panorâmica e crítica da história brasileira da interpretação e da tradução para os leigos neste domínio" (SILVA-REIS; MILTON, 2016, p. 2). O mesmo acontece com o artigo estruturado por séculos de Silva-Reis e Bagno (2016) em relação à história dos intérpretes desde o século XVI até o século XIX, cujo objetivo é destacar “o papel desses agentes culturais para uma reescrita da história da tradução no Brasil" (SILVA-REIS; BAGNO, 2016, p. 81).

Essas panorâmicas da história da tradução oral e escrita convivem com novas tendências. Um dos campos mais inovadores é o da história visual da tradução (SILVA-REIS, 2017), centrado na iconografia do século XIX de pintores que representam cenas de momentos diferentes do passado colonial. É curioso observar como Silva-Reis sublinha o interesse ainda recente pela história da tradução no Brasil “desenvolvida por inúmeros pesquisadores" e, sobretudo, a novidade do estudo da imagem como "indício histórico" (SILVA-REIS, 2017, p. 1477). A iconografia surge, assim, como ramo historiográfico e método analítico de escrita da história, cujo inspirador é Jean Delisle (1997-1998).

Outros âmbitos explorados por Silva-Reis ${ }^{4}$ são as relações entre a tradução e a negritude em número especial elaborado em parceria com Lauro Maia Amorim para a revista Cadernos de Literatura em Tradução (SILVA-REIS; AMORIM, 2016), em que os organizadores apontam a necessidade de resgatar o labor dos tradutores negros e as traduções de literatura negra para a história da tradução do Brasil. Este tema complementa-se com dois trabalhos recentes de Silva-Reis: o primeiro, em parceria com Cibele de Guadalupe Sousa Araújo, publicado na Revista da Anpoll (SILVA-REIS; ARAÚJO, 2018), explora a relação entre os Estudos da Tradução e os Estudos da Diáspora Negra, propondo um itinerário brasileiro de princípios teóricos; o segundo, publicado em Tradução em Revista (SILVAREIS, 2018), versa sobre o intérprete negro na história da tradução oral.

\footnotetext{
${ }^{4}$ A consulta do blogue de Dennys Silva-Reis - <http://historiografiadatraducaobr.blogspot.com> - é um documento fundamental para testar o estado da pesquisa histórica em tradução no Brasil.
} 
Podem ainda ser citados os trabalhos historiográficos publicados pela professora Germana Henriques Pereira, da Universidade de Brasília, na coleção Estudos da Tradução da Pontes Editores (por exemplo, PEREIRA; VERÍSSIMO, 2017), bem como outras revistas que divulgam trabalhos sobre a história da tradução e da interpretação (por exemplo, Belas Infiéis, Cadernos de Tradução ou Tradução em Revista).

Apesar do exposto, a história da tradução brasileira é uma história "ainda não contada", como comentam Damiana Rosa de Oliveira e Andreia de Jesus Cintas Vazquez, em A Fantástica História (ainda não contada) da Tradução no Brasil (2018). A obra apresenta-se como um passeio que tenta resgatar o tradutor ao longo da história desde a chegada dos portugueses até os nossos dias e denuncia a falta de visibilidade dos mediadores. Trata-se de um livro de divulgação dividido em dez partes, acompanhado de ilustrações, que evidencia figuras menos conhecidas como as mulheres intérpretes e tradutoras (Bartira, mulher indígena de João Ramalho; Damiana Menezes da Cunha; Dionísia Gonçalves Pinto, tradutora de textos feministas no século XVIII; ou a imperatriz D. Leopoldina); ou como o primeiro tradutor juramentado Ildefonso José da Costa; o imperador Dom Pedro II como tradutor literário; o político tradutor Rui Babosa de Oliveira e os primeiros tradutores das línguas africanas e do japonês ou a tradução midiática e em tempos da globalização.

\section{O que falta pesquisar? Algumas propostas}

Após a revisão bibliográfica acima realizada, é possível apresentar um balanço que deve ser considerado apenas como uma amostra representativa da investigação que está sendo desenvolvida nos nossos dias: dois livros que oferecem visões gerais (WYLER, 2003; OLIVEIRA; VAZQUEZ, 2018); um artigo-roteiro com muita informação panorâmica sobre a história da tradução oral e escrita (SILVA-REIS; MILTON, 2016) e outro que organiza a história da interpretação (SILVA-REIS; BAGNO, 2016), ambos ordenados cronologicamente por séculos; dois livros coletivos que recolhem trabalhos de congressos (MILTON, 2001; PEREIRA; VERÍSSIMO, 2017) e um número especial de revista sobre historiografia da tradução (MILTON; MARTINS, 2010), além de artigos sobre questões mais específicas como a história visual 
da tradução ou dos intérpretes negros (SILVA-REIS, 2017, 2018), bem como outros muitos trabalhos focados na recepção de autores estrangeiros e obras traduzidas, na análise de traduções e nas concepções teóricas da tradução de tradutores, poetas e escritores.

Nesse contexto, observamos um predomínio dos estudos monográficos sobre os estudos globais e uma escassez de trabalhos que aprofundem o estudo dos períodos da história e que analisem mais detalhadamente os dados fornecidos pelas visões panorâmicas. Muitos são os caminhos apontados, porém, a tarefa ainda é imensa: seria preciso a formação de equipes maiores e grupos de pesquisa para desenvolver um programa de investigação capaz de alicerçar as bases de uma história da tradução oral e escrita no Brasil.

Tendo em vista essas considerações, elencamos algumas propostas para futuros projetos:

a) Elaboração de uma bibliografia da história da tradução no Brasil ou a arqueologia daquilo que foi traduzido, como fez António A. Gonçalves Rodrigues em cinco volumes para a história das traduções de Portugal em que deixou de fora o Brasil (RODRIGUES, 1992-1999).

b) Elaboração de um dicionário histórico da tradução do Brasil, à semelhança do dicionário editado na Espanha por Lafarga e Pegenaute (2009): o que foi traduzido; quem traduziu (tradutores, agentes, intermediários, críticos, teóricos etc.); verbetes para as traduções do tupi e outras línguas; modalidades de tradução (literária, científica, técnica, econômica, juramentada, informática, audiovisual, mídia) e de interpretação (consecutiva, simultânea, bilateral, de conferências, de língua de sinais); entradas específicas para o ensino e a formação de tradutores e intérpretes, instituições, revistas ou congressos.

c) Elaboração de um dicionário de tradutores, um projeto que alargue o Dicionário de tradutores literários no Brasil, do Grupo de Pesquisa Literatura Traduzida, publicação em linha de responsabilidade do Núcleo de Tradução da UFSC.

d) Para uma história da tradução do Brasil:

- Exploração de fontes de diversas obras de história: histórias do Brasil, da língua, da ciência ou da literatura. Com relação à literatura, 
Alfredo Bosi inclui apenas um apartado para as traduções poéticas no fim de sua história concisa (BOSI, 2017, p. 523-525) e poucas são as referências à tradução nos cinco volumes de Sílvio Romero (1980).

- Revisão das fontes historiográficas dos séculos XVI a XVIII, sobretudo, para a tradução oral: Pero Vaz de Caminha, Carta de 1500 (publicada pela primeira vez em 1817), Relação do piloto anônimo de 1500 (publicada em 1507), Pero Lopes e Sousa, Diário de Navegação (1530), Pero de Magalhães Gândavo, Tratado da Terra do Brasil de 1570 (publicado em 1826) e a História da Província de Santa Cruz a que Vulgarmente Chamamos Brasil (1576), Fernão Cardim, Tratados da Terra e da Gente do Brasil (1584), Gabriel Soares de Sousa, Tratado Descritivo do Brasil (1587), Ambrósio Fernandes Brandão, Diálogos das Grandezas do Brasil (inícios século XVII, só publicado em 1930), Frei Vicente do Salvador, História do Brasil de 1627 (inédita até 1889, é considerada a primeira obra de história brasileira), André João Antonil, Cultura e opulência do Brasil (1711), Sebastião da Rocha Pita, História da América Portuguesa (1730); fontes missionárias dos jesuítas: José de Anchieta, Arte de gramática da lingoa mais usada na costa do Brasil (1595), Manuel da Nóbrega, Cartas do Brasil (1549-1560); exploração dos relatos de viajantes como Hans Staden, Viagem ao Brasil (1557, tradução de Alberto Löfgren), Jean de Léry, Viagem à terra do Brasil (1574, tradução de Sérgio Milliet), André Thévet, Singularidades da França Antártica (1557, tradução de Estêvão Pinto) ou Anthony Knivet, As incríveis aventuras e estranhos infortúnios de Anthony Knivet (1591, tradução de Vivien Kogut Lessa de Sá), além de outras crônicas, relatos de viagem, cartas, memórias, diários e álbuns de desenhos. Segundo Gaspar, existem mais de 260 obras, em várias línguas, nas quais os autores retratam os habitantes, a vida social, os usos e os costumes, a fauna, a flora e outros aspectos da antiga colônia portuguesa, principalmente durante o século XIX.

e) Entre os possíveis temas que integrariam uma história da tradução brasileira, podemos mencionar:

- O papel das traduções: recepção e função dos textos traduzidos no sistema brasileiro; as mudanças provocadas pelas traduções e as consequências - estéticas, ideológicas, culturais - da transnaturalização; a retradução (MILTON; TORRES, 2003); as traduções indiretas; a comparação 
e a análise de traduções de um mesmo texto em épocas diferentes; as traduções invisíveis.

- Imagens dos religiosos/colonos e dos colonizados (índios) através da tradução. A tradução e o poder. A tradução e o escravismo. A tradução e a violência: documentos relativos a situações de conflito e de guerra, declarações, acordos. Tradução e censura em diferentes períodos: época da Inquisição, da Real Mesa Censória, do Estado Novo, da ditadura (1964-1989). A autocensura e as normas de tradução e os seus efeitos. A autotradução. A pseudotradução. A não-tradução. A tradução e a introdução de novos gêneros (como os gêneros e estilos europeus foram moldando a expressão da nova sociedade, houve influência das belas infiéis?). A ciência e a tradução (RODRIGUES, 2010). A tradução e as elites (WYLER, 2003).

f) Tradutores e intérpretes na ficção (por exemplo, o língua Diogo Álvares Correia, que inspirou o poema Caramuru (1781) de frei José de Santa Rita Durão).

g) História dos tradutores: aborgadem individual, por geração, escola ou grupo. Os filólogos e a tradução. Os escritores e a tradução: Machado de Assis (MASSA, 2008). Os teóricos: Paulo Rónai (ESQUEDA, 2004).

h) História do pensamento tradutório: conceitos e terminologia do traduzir e interpretar; tipologias: tradução, versão, adaptação, imitação, apropriação, paráfrase, plágio, pseudotradução. Imagens e metáforas da tradução. Como foi a importação de teorias eurocêntricas para o espaço brasileiro? Elaboração de obras antológicas (MARTINS; GUERINI, 2018).

i) História da interpretação. Línguas e intérpretes: tipos e denominações (SILVA-REIS; BAGNO, 2016). A história do tradutor público, comercial e juramentado (OLIVEIRA, 2005). A história e as modalidades da prática da interpretação (QUENTAL; SILVA; ARAUJO, 2018). A tradução/interpretação na Administração. A interpretação de conferências (PAGURA, 2010).

j) Historiografia contemporânea. Frota tinha assinalado duas grandes subáreas na historiografia que vem sendo desenvolvida no campo da tradução: a da própria disciplina e a da práxis tradutória, incluídas as suas funções e modalidades diversas e os diferentes papéis e identidades do 
tradutor (FROTA, 2007, p. 156). Poderia acrescentar-se um estudo da historiografia que está sendo realizada no Brasil.

k) Por fim, a ética é também um tema a ser pesquisado e pode figurar nos discursos e práticas dos tradutores, apresentando-se de maneira implícita, seja por meio das suas escolhas ou das informações que evidenciam ou silenciam.

\section{O que caracteriza a História da Tradução do Brasil?}

Com base no que foi exposto, podemos nos interrogar: por que é importante estudar a história da tradução? Para que tanto esforço por recuperar o passado? Qual a utilidade dos estudos históricos? A pesquisa histórica procura uma interpretação do passado a partir de documentos autênticos com vistas a alcançar um melhor conhecimento do presente, quer da disciplina, enquadrando os avanços teóricos em uma perspectiva evolutiva, quer da própria cultura, explicando o que nos aproxima e nos distancia das outras culturas e tradições. Uma prática marginal e até periférica como a tradução, que opera entre línguas, culturas e sociedades de épocas diversas, constitui um terreno privilegiado para analisar as relações complexas que conformam uma cultura determinada, no caso em questão, a cultura brasileira. Neste processo, surgem mais interrogações: há um modo de traduzir brasileiro? (WYLER, 1999). Que aproximações teóricas definem melhor a pesquisa historiográfica atual no Brasil? Será a desconstrução? O enfoque pós-colonial? Os estudos culturais? Os estudos feministas? Os estudos sobre as minorias raciais? Os estudos descritivos e sua incidência na literatura traduzida? Segundo Walter Carlos Costa, os Estudos da Tradução no Brasil caracterizam-se "pela coexistência de diferentes abordagens e o desenvolvimento de diferentes interfaces da disciplina" 5 (LÁZARO IGOA, 2014, p. 228). Numa entrevista concedida a Lázaro Igoa, Costa aponta algumas das linhas mais emergentes, entre elas, os estudos descritivos, a pesquisa em tradução literária (com relevo para a tradução poética e a tradução comentada), a história da tradução ou a tradução da língua de

\footnotetext{
${ }^{5}$ Tradução própria do original: "por la convivencia de distintos enfoques y el desarrollo de distintas interfaces de la disciplina" (LÁZARO IGOA, 2014, p. 228).
} 
sinais. Junto com a adaptação das propostas de tradutólogos como Jean Delisle, Lieven D'hulst, Anthony Pym ou Lawrence Venuti, constata-se um leque de tendências próprias da investigação histórica no Brasil. Especialmente interessantes são as relações entre edição de livros e tradução (com o trabalho precursor de Milton (2002) sobre as traduções do Clube do Livro), o auge das traduções comentadas (uma pesquisa recorrente em dissertações e teses), a análise de traduções em línguas indígenas, sobretudo o nheengatu, além do campo imenso da pesquisa em história da interpretação.

Se quisermos caracterizar a história da tradução do Brasil, surgem mais perguntas que respostas: quais os focos de tradução? Como influiu o tardio estabelecimento da imprensa na evolução da tradução no Brasil? E a criação tardia de universidades? Será uma história da tradução mais oral que escrita, isto é, uma tradução dependente durante séculos da oralidade e, portanto, mais invisível e difícil de sistematizar? Não seria mais apropriado falar em história da tradução "luso-brasileira" para todo o período colonial? Como a tradução serviu para unificar o país e influiu na coesão linguística? Em que ajudou a tradução no processo civilizatório e sociocultural do Brasil? Podemos falar de diferentes 'Brasis', como propõe Darcy Ribeiro (2017), a partir da tradução? Qual foi o papel da tradução nas diversas fronteiras do Brasil e nos contatos com os países da América Espanhola? As perguntas são muitas e diversas, todas elas descontínuas, como a história, que é feita de avanços e recuos e, por isso, precisa ser reconstruída e interpretada constantemente; e ainda mais perguntas poderiam ser colocadas, somadas ao empolgante desafio que é historiar a tradução brasileira.

\section{Referências}

BARBOSA, Heloísa Gonçalves; WYLER, Lia. Brazilian Tradition. In: BAKER, Mona; MALMKJÆR, Kirsten. (Eds.). Encyclopedia of Translation Studies. London: Routledge, 1998, p. 326-333.

BERMAN, Antoine. La traduction et ses discours. Meta: Journal des Traducteurs, Montreal, v. 34, n. 4, p. 672-679, 1989. 
BOSI, Alfredo. História concisa da literatura brasileira. 51. ed. São Paulo: Editora Cultrix, 2017.

DELISLE, Jean. Réflexions sur l'historiographie de la traduction et ses exigences scientifiques. Équivalences, Bruxelas, v. 26, n. 2 ; v. 27, n. 1, p. 2143, 1997-98.

D'HULST, Lieven. Why and How to Write Translation Histories. In: MILTON, John. (Ed.). Emerging Views on Translation History in Brazil. São Paulo: Humanitas, FFLCH/USP, 2001, p. 21-32. Translation history. In: GAMBIER, Yves; VAN DOORSLAER, Luc. (Eds.). Handbook of Translation Studies. John Benjamins: Amsterdam/Filadelfia, 2010, p. 397-405.

ESQUEDA, Marileide. O tradutor Paulo Rónai: o desejo da tradução e do traduzir. 2004. 210 f. Tese de Doutorado (Linguística Aplicada), Universidade Estadual de Campinas, São Paulo.

FROTA, Maria Paula. Um balanço dos estudos da tradução no Brasil. Cadernos de Tradução, Florianópolis, v. 1, n. 19, p. 135-169, 2007.

GASPAR, Lúcia. Viajantes (relatos sobre o Brasil, século XVI a XIX). Disponível em:

http://basilio.fundaj.gov.br/pesquisaescolar/index.php?option=com_content \&id=131. Acesso em 4 jun. 2019.

GUERINI, Andréia; TORRES, Marie-Hélène; COSTA, Walter Carlos. (Orgs.). Os Estudos da Tradução no Brasil nos Séculos XX e XXI. Florianópolis: PGET/UFSC, 2013.

HISTAL. História da Tradução na América Latina. Disponível em: http://www.histal.net. Acesso em 4 jun. 2019.

HOLMES, James. Translated! Papers in Literary Translation and Translation Studies. Amsterdam: Rodopi, 1988.

HURTADO ALBIR, Amparo. Perspectivas de los estudios sobre la traducción. In: (Ed.). Estudis sobre la traducció. Universitat Jaume I, Castellón de la Plana, 1994, p. 25-41.

LAFARGA, Francisco; PEGENAUTE, Luis (Eds.). Diccionario histórico de la traducción en España. Madrid: Gredos, 2009.

(Eds.). Aspectos de la traducción en Hispanoamérica: autores, traducciones y traductores. Vigo: Academia del Hispanismo, 2012a. 
(Eds.). Lengua, cultura y política en la historia de la traducción en Hispanoamérica. Vigo: Academia del Hispanismo, 2012b.

(Eds.). Diccionario histórico de la traducción en Hispanoamérica. Madrid/Frankfurt: Iberoamericana/Vervuert, 2013.

LAMBERT, Jose. History, Historiography and the Discipline: A Programme. In: GAMBIER, Yves; TOMMOLA, Jorma. (Eds.). Translation and Knowledge. Scandinavian Symposium on Translation Theory IV (6-6-1992). Turku: University of Turku/Centre for Translation and Interpreting, 1993, p. 3-25.

LÁZARO IGOA, Rosario. Los Estudios de la Traducción en Brasil: entrevista al Profesor Walter Carlos Costa. Mutatis Mutandis, Medellín, v. 7, n. 1, p. 223-231, 2014.

MARTINS, Marcia. As relações nada perigosas entre história, filosofia e tradução. Cadernos de Tradução, Florianópolis, v. 1, n. 1, p. 37-51, 1996.

. Os Estudos da Tradução no Brasil. In: TELES, Gilberto Mendonça. (Coord.). Diálogos ibero-americanos. Rio de Janeiro: Galo Branco, 2005.

; GUERINI, Andréia. (Orgs.). Palavra de tradutor: reflexões sobre tradução por tradutores brasileiros. Florianópolis: Editora da UFSC, 2018. MILTON, John (Ed.). Emerging Views on Translation History in Brazil. São Paulo: Humanitas, FFLCH/USP, 2001.

. O Clube do Livro e a tradução. São Paulo: EDUSC, 2002.

. Los Estudios de Traducción en Brasil. Mutatis Mutandis, Medellín, v. 7, n. 1, p. 3-15, 2014.

; MARTINS, Marcia. Apresentação - Contribuições para uma historiografia da tradução. Tradução em Revista, Rio de Janeiro, n. 8, p. 110, 2010.

; TORRES, Marie-Hélène (Orgs.). Tradução, retradução e adaptação.

Cadernos de Tradução, Florianópolis, v. 1, n. 11, 2003.

MASSA, Jean-Michel. Machado de Assis Tradutor. Belo Horizonte: Crisálida, 2008.

OLIVEIRA, Luiz Eduardo de. As origens da profissão de tradutor público e intérprete comercial no Brasil (1808-1943). Claritas, São Paulo, p. 1-16, 2005. 
OLIVEIRA, Damiana Rosa de; VAZQUEZ, Andreia de Jesus Cintas. A Fantástica História (ainda não contada) da Tradução no Brasil. São Paulo: Transitiva, 2018.

OLIVEIRA HARDEN, Alexandra Ramos de. Brasileiro tradutor e/ou traidor: frei José Mariano da Conceição Veloso. Cadernos de Tradução, Florianópolis, v. 1, n. 23, p. 131-148, 2009.

. Manuel Jacinto Nogueira da Gama: ciência e tradução no final do século XVIII. Tradução em Revista, Rio de Janeiro, v. 1, p. 1-19, 2010.

Os tradutores da Casa do Arco do Cego e a ciência iluminista: a conciliação pelas palavras. Trabalhos de Linguística Aplicada, São Paulo, v. 50, n. 2, p. 301-320, 2011.

PAES, José Paulo. Tradução: a ponte necessária. São Paulo: Ática, 1990.

PAGANO, Adriana. As pesquisas historiográficas em tradução. In:

(Org.). Metodologias de pesquisa em tradução. Belo Horizonte: FALEUFMG, 2001.

; VASCONCELLOS, Maria Lúcia. Estudos da Tradução no Brasil: reflexões sobre teses e dissertações elaboradas por pesquisadores brasileiros nas décadas de 1980 e 1990. DELTA, São Paulo, n. 19: Especial, p. 1-25, 2003. PAGNI, Andrea. Hacia una historia de la traducción en América Latina. Iberoamericana, Madrid/Frankfurt, v. XIV, n. 56, p. 205-224, 2014.

PAGURA, Reynaldo José. A interpretação de conferências no Brasil: história de sua prática profissional e a formação de intérpretes brasileiros. 2010. 231 f. Tese de Doutorado (Estudos Linguísticos e Literários do Inglês). Faculdade de Filosofia, Letras e Ciências Humanas, Universidade de São Paulo.

PEREIRA, Germana Henriques; VERISSIMO, Thiago André (Orgs.). História e Historiografia da Tradução: Desafios para o Século XXI. Campinas: Pontes Editores, 2017.

PINILLA, José Antonio Sabio; PULIDO, Marta et al. A metodologia em História da Tradução: Estado da questão. Belas Infiéis, Belo Horizonte, v. 6, n. 2, p. 223-255, 2017.

QUENTAL, Raffaella de Filippis; SILVA, Christiano Sanches do Valle; ARAUJO, Denise de Vasconcelos. Apresentação - Estudos da Interpretação 
em revista: história e modalidades de prática. Tradução em Revista, Rio de Janeiro, v. 24, n. 1, p. 1-4, 2018.

RIBEIRO, Darcy. O povo brasileiro. A formação e o sentido do Brasil. 3. ed. 3. reimpressão. São Paulo: Global Editora, 2017.

RODRIGUES, António Augusto Gonçalves. A Tradução em Portugal tentativa de resenha cronológica das traduções impressas em língua portuguesa, excluindo o Brasil de 1495 a 1959. Vol. I. 1495-1834. Lisboa, Imprensa Nacional-Casa da Moeda, 1992.

A Tradução em Portugal. Vol. II. 1835-1850. Lisboa: Instituto de Língua e Cultura Portuguesa, 1992.

A Tradução em Portugal. Vol. III. 1851-1870. Lisboa: ISLA, 1993.

A Tradução em Portugal. Vol. IV. 1871-1900. Lisboa: ISLA, 1994.

A Tradução em Portugal. Vol. V. 1901-1930. Lisboa: ISLA, 1999.

RODRIGUES, Cristina Carneiro. O papel da tradução na pesquisa científica brasileira: primeiros movimentos. Tradução em Revista, Rio de Janeiro, n. 1, p. 1-13, 2010.

ROMERO, Sílvio. História da literatura brasileira. 7. ed. Rio de Janeiro: José Olympio, 1980.

SERUYA, Teresa. Contributos para uma história da tradução em Portugal. In: ORDÓÑEZ LÓPEZ, Pilar; SABIO PINILLA, José Antonio. (Ed. Lit.). Historiografía de la traducción en el espacio ibérico: textos contemporáneos. Cuenca: Ediciones de la Universidad de Castilla-La Mancha, 2015, p. 221-241.

SILVA-REIS, Dennys. História Visual da Tradução: a iconografia do século XIX no Brasil. Domínios de Lingu@gem, Uberlândia, v. 11, n. 5, p. 1475-1504, 2017.

O intérprete negro na história da tradução oral: da tradição africana ao colonialismo português no Brasil. Tradução em Revista, Rio de Janeiro, v. 24, n. 1, p. 1-42, 2018.

; AMORIM, Lauro Maia. Negritude e tradução no Brasil. O legado do Barão de Jacuecanga. Cadernos de Literatura em Tradução, São Paulo, n. 16, p. 7-18, 2016.

; ARAÚJO, Cibele de Guadalupe Sousa. Translation Studies and Black Diaspora Studies: a Brazilian itinerary / Estudos da Tradução e Estudos de 
Diáspora Negra: um itinerário brasileiro. Revista da Anpoll, Santa Catarina, v. 1, n. 44, p. 83-99, 2018.

; BAGNO, Marcos. Os intérpretes e a formação do Brasil: os quatro primeiros séculos de uma história esquecida. Cadernos de Tradução, Florianópolis, v. 36, n. 3, p. 81-108, 2016.

; MILTON, John. História da tradução no Brasil: percursos seculares.

Translatio, Porto Alegre, n. 12, p. 2-42, 2016.

TOURY, Gideon. What are Descriptive Studies into Translation Likely to Yield apart from Isolated Descriptions? In: LEUVEN-SWART, Kitty van; NAAIJKENS, Ton (Eds.). Translation Studies: The State of the Art. Amsterdam-Atlanta: Rodopi, 1991, p. 179-192.

Descriptive Translation Studies and Beyond. Amsterdam: Benjamins, 1995.

VANDEPITTE, Sonia. Remapping Translation Studies: Towards a Translation Studies Ontology. Meta: Journal des Traducteurs, Montreal, v. 53, n. 3, p. 569-588, 2008.

WYLER, Lia. Um modo de traduzir brasileiro? Cadernos de Tradução, Florianópolis, v. 1, n. 4, p. 263-275, 1999.

. Línguas, poetas e bacharéis: uma crônica da tradução no Brasil. Rio de Janeiro: Rocco, 2003.

A Promising Research Ground: Translation Historiography in Brazil. Meta: journal des traducteurs, Montreal, v. 50, n. 3, p. 851-857, 2005.

\section{Resumo}

Este artigo, que tem como tema a história da tradução do Brasil, estrutura-se em três partes: a primeira mostra a importância da História da Tradução para a disciplina dos Estudos da Tradução; a segunda comenta alguns trabalhos mais relevantes do século XXI sobre a história da tradução brasileira com vistas a avaliar o que foi pesquisado; e a terceira aponta algumas linhas futuras de pesquisa. $\mathrm{O}$ artigo conclui tentando caracterizar alguns aspectos da história da tradução do Brasil.

Palavras-chave: História da Tradução; Estudos da Tradução; Brasil; Propostas de pesquisa. 


\section{Resumen}

Este artículo tiene como tema la historia de la traducción de Brasil y está estructurado en tres partes: la primera muestra la importancia de la Historia de la Traducción para la disciplina de los Estudios de Traducción; la segunda comenta algunos trabajos más relevantes del siglo XXI sobre la historia de la traducción brasileña a fin de valorar lo que se ha investigado y la tercera apunta algunas líneas futuras de investigación. El artículo concluye con un intento de caracterizar algunos aspectos de la historia de la traducción de Brasil.

Palabras clave: Historia de la Traducción; Estudios de Traducción; Brasil; Propuestas de investigación. 